\title{
I-beam girders dimensioning with numerical modelling of local stresses in wheel-supporting flanges
}

\author{
D. Gąska*, T. Haniszewski**, J. Margielewicz*** \\ *Silesian University of Technology, Krasińskiego 8,40-019 Katowice, Poland, E-mail: damian.gaska@polsl.pl \\ **Silesian University of Technology, Krasińskiego 8,40-019 Katowice, Poland, E-mail: tomasz.haniszewski@polsl.pl \\ ***Silesian University of Technology, Krasińskiego 8,40-019 Katowice, Poland, E-mail: jerzy.margielewicz@polsl.pl \\ cross $^{\text {ref }}$ http://dx.doi.org/10.5755/j01.mech.23.3.14083
}

\section{Introduction}

In various industrial transport systems lightweight cranes or portable hoists with stationary tracks are used to move cargo. These devices require special supporting structures in the form of roads, mostly I-beams, whose characteristic feature is the local load at the bottom flange of the beam section - the forces coming from the wheels of the crane or hoist trolley. Therefore, the design process of the supporting structure for the hoist or overhead crane should take into account additional components of the stresses from the local bending of the free cross-sectional portions of the I-beam or box girder.

One-girder roadways have been applied [1-5]:

- in cranes with load capacity $<25 \mathrm{t}$ and span $<25 \mathrm{~m}$;

- in overhead conveyors (single and dual);

- in suspended mining railways.

Cranes in which there is a girder in the form of an I-beam are widely used in industry due to their small size, their weight and the ensuing price. The I-beam girder is used as both a winch roadway for moving a rail mounted on the beam and a suspended hoist on the lower flange. Despite the lightness of construction, however, compared with boxgirders, they are characterized by greater slenderness and are therefore not suitable for overhead cranes with large spans and payloads [6-16]. The typical scope of this type of overhead crane is therefore usually limited to payloads $<12.5 \mathrm{t}$ (although there are also hoists with a capacity of $25 \mathrm{t}$ ) and a span $<25 \mathrm{~m}$, with low operating speed and intensity of work [1,2]. Such parameters are sufficient, however - in an era of high performance with a desire to reduce costs - for regimes that are able to meet the requirements of most manufacturing processes and handling in industrial plants.

The design solution used more often at present is to use the bottom shelf structures in the I-beam girder as the road for the hoist (which is practically obligatory in the case of cranes with one girder). Another possible solution is to use the upper plane, with a rail mounted as a roadway for the winch. This is the preferred solution for larger loads, but it is more time-consuming and expensive to produce.

Frequently girders are constructed from normal hot-rolled beams with sloping flanges, along which a conical or spherical wheel with one flange or without flanges rolls (Fig. 1, a). There are also I-beams in the form of a parallel-flange beam, along which a roller wheel of the overhead hoist rolls (Fig. 1, b). The lower flanges, depending on the analysis of the girder effort, should have a slightly greater thickness due to the:

- relatively higher stress at the free edge of the flanges;

- the occurrence of additional contact stresses at the moment when hoist wheels are passing;

- abrasive-adhesion wear of the upper surface of the lower flange plates from contact with the hoist wheels.

Accordingly, a special welded I-beam girder construction has been introduced, consisting of two different Tbars (Fig. 1, c). The lower T-beam has thicker shelves, with cylindrical undercuts at the transition of the web plates. Undercutting of the radius will attenuate the corresponding notch, and will have a beneficial effect on the fatigue strength and durability of the girder. Additionally, the hardening surface of the shelf can also be used for improving durability, thereby reducing the wear due to contact with wheels [2].

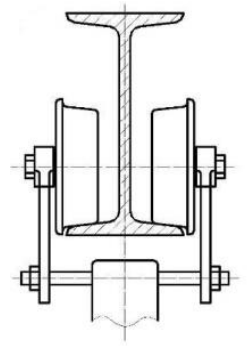

a

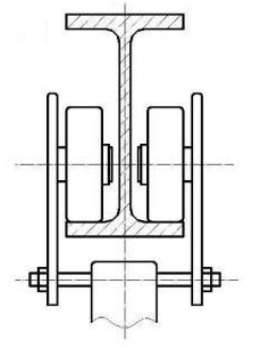

b

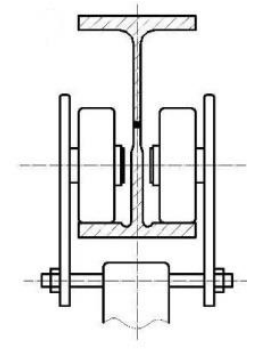

C
Fig. 1 Cross-sections of the main girder in hoisting cranes: a - from I-beam according to PN-EN 10024:1998; b-parallel-flange I-beam according to PN-EN 10034:1996; c - of welded construction from two T-bars according to PN-EN 10055:1999

\section{Components of the stress state from the local load from wheel pressure}

In calculating the strength of the beams for suspended transport equipment, the special work of locally loaded lower flanges of the girder must also be taken into account. Apart from the general main bending stress acting in the X direction (Fig. 2, a), also local deflection of the flanges appears. There will then be at least a biaxial stress state at the lower flanges (Fig. 2, b) due to the appearance of additional stress in the $\mathrm{Y}$ direction.

According to [17-19], when the bottom flange is reinforced with a welded metal sheet of similar thickness to the width and length, then it can be assumed that the stresses, in accordance with formulas (1-5), are sufficient in order to check the beam effort. For long reinforcements welded to the bottom flange there is no specific guidance in 
the standards for the analytical design of cranes.

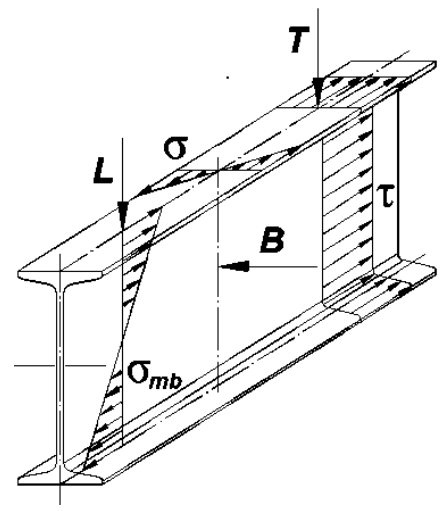

a

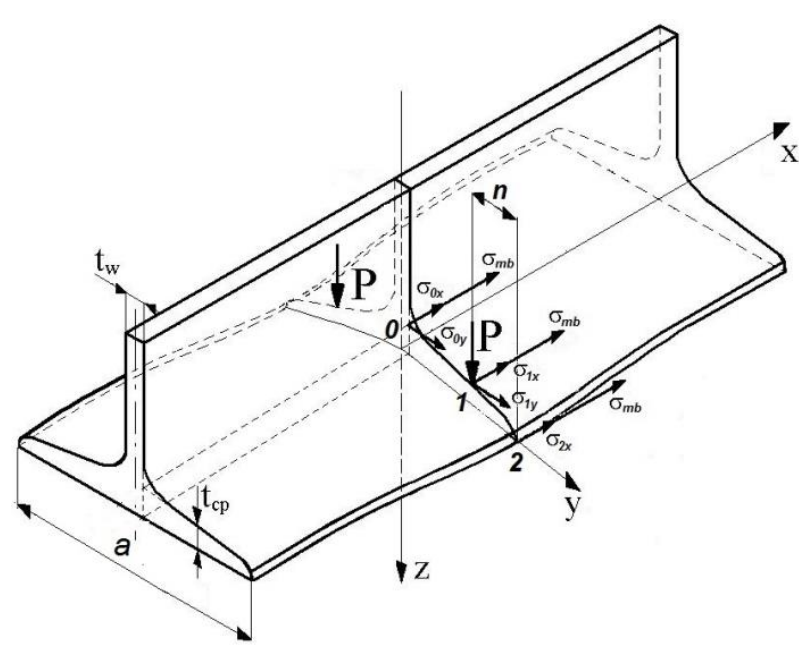

b

Fig. 2 Method of load and components of the stress state in the I-beam: a - without affecting the local bending of the bottom flange; $b$ - in the case of local bending of the lower flange. $\sigma_{0 x}, \sigma_{1 x}, \sigma_{2 x}, \sigma_{0 y}, \sigma_{1 y}$-stresses from local bending at points $0,1,2 . \sigma_{m b}$ - stress from main bending of the girder; $\tau$-shear stress; $L$-vertical bending force; $T$-shearing force; $B$ - horizontal bending force; $P$ - local bending force

In the model calculation, the flanges can be considered as an infinitely long plate constrained at the point of transition from web to flange and with a free edge at the end. For such an adopted model the greatest normal stress from bending the flange of local bending force $P$ (the pressure of a pair of wheels) occurs:

- in the cross-section, where the transition from web to flange occurs (point 0, Fig. 2, b) and amounts to:

- in the YZ plane in the direction of the y-axis:

$$
\sigma_{0 y}=\frac{c_{0 y} P}{t_{c p}^{2}}
$$

- in the $\mathrm{XZ}$ plane in the direction of the $\mathrm{X}$-axis:

$$
\sigma_{0 x}=\frac{c_{0 x} P}{t_{c p}^{2}}
$$

- in the cross-section, where the wheel load is (point 1, Fig. 2, b) and amounts to:

- in the $\mathrm{YZ}$ plane in the direction of the $\mathrm{y}$-axis:

$$
\sigma_{1 y}=\frac{c_{1 y} P}{t_{c p}^{2}}
$$

- in the $\mathrm{XZ}$ plane in the direction of the $\mathrm{X}$-axis:

$$
\sigma_{1 x}=\frac{c_{1 x} P}{t_{c p}^{2}}
$$

Fig. 2, b):

- at the end of the flange and amounts to (point 2,

- in the XZ plane in the direction of the $\mathrm{X}$-axis:

$$
\sigma_{2 x}=\frac{c_{2 x} P}{t_{c p}^{2}}
$$

\begin{tabular}{|c|c|c|}
\hline & Stresses & Values of $c_{i}$ factors \\
\hline \multirow{2}{*}{ 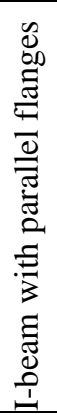 } & \begin{tabular}{|l|} 
Longitudi- \\
nal bending \\
stresses \\
(X direc- \\
tion)
\end{tabular} & $\begin{array}{l}c_{0 x}=0.050-0.580 \lambda+0.148 e^{3.015 \lambda} \\
c_{1 x}=2.230-1.490 \lambda+1.390 e^{-18.33 \lambda} \\
c_{2 x}=0.730-1.580 \lambda+2.910 e^{-6.00 \lambda}\end{array}$ \\
\hline & $\begin{array}{l}\text { Transverse } \\
\text { bending } \\
\text { stresses } \\
\text { (Y direc- } \\
\text { tion) } \\
\end{array}$ & $\begin{array}{l}c_{0 y}=-2.110+1.977 \lambda+0.0076 e^{6.53 \lambda} \\
c_{1 y}=10.108-7.408 \lambda-10.108 e^{-1.364 \lambda}\end{array}$ \\
\hline \multirow{2}{*}{ 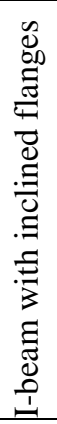 } & \begin{tabular}{|c|} 
Longitudi- \\
nal bending \\
stresses \\
(X direc- \\
tion) \\
\end{tabular} & $\begin{array}{l}c_{0 x}=-0.981-1.479 \lambda+1.120 e^{1.322 \lambda} \\
c_{1 x}=1.810-1.150 \lambda+1.060 e^{-7.70 \lambda} \\
c_{2 x}=1.990-2.810 \lambda+0.840 e^{-4.69 \lambda}\end{array}$ \\
\hline & $\begin{array}{l}\text { Transverse } \\
\text { bending } \\
\text { stresses } \\
\text { (Y direc- } \\
\text { tion) }\end{array}$ & $\begin{array}{l}c_{0 y}=-1.096+1.095 \lambda+0.192 e^{-6.00 \lambda} \\
c_{1 y}=3.965-4.835 \lambda-3.965 e^{-2.675 \lambda}\end{array}$ \\
\hline & & $\lambda=\frac{n}{0.5\left(a-t_{w}\right)}$ \\
\hline
\end{tabular}

where $c_{i}$ factors are calculated according to Table 1 .

Table 1

Values of $c_{i}$ factors [20]

\section{General rules for design of the main girder of underslung cranes}

According to [21], the material of the beam crosssection of the crane must be chosen so that at the occurrence of a single computational load, taking into account the partial safety factors $\gamma_{p}$, respectively combined according to [22], while the occurrence of biaxial normal stress ( $\sigma_{x}$ and $\sigma_{y}$ ) and the shear stress $\tau$-condition is satisfied:

$$
\left(\frac{\sigma_{S d, x}}{f_{R d, x}}\right)^{2}+\left(\frac{\sigma_{S d, y}}{f_{R d, y}}\right)^{2}-\frac{\sigma_{S d, x} \sigma_{S d, y}}{f_{R d, x} f_{R d, y}}+\left(\frac{\tau_{S d}}{f_{R d}}\right)^{2} \leq 1.0,
$$


in directions $\mathrm{x}$ and $\mathrm{y} ; f_{R d}$ - limit design shear stress, $\sigma_{S d, x}$, $\sigma_{S d, y}, \tau_{S d}$ - are the design stresses.

When calculating the stress, it is necessary to include all internal forces occurring in the load-carrying system:

a) for the calculation of the normal stresses: axial force, bending moment and bimoment;

b) for the calculation of shear stress: shear force and torque.

For the dimensioning of the main girder of the underslung crane, further stress of the local flanges bending according to the formulas (1-5) should be considered. The local stresses can be reduced by one quarter because of the extra plastic bending capacity of the flange plate or the extra plastic tension capacity of the web. Then the condition (6), when checking the cross-section, takes the form (compare Fig. 2):

- for point 0 according to Fig. 2, b:

$$
\begin{aligned}
& \left(\frac{\sigma_{m b}+0.75 \sigma_{0 x}}{f_{R d, x}}\right)^{2}+\left(\frac{0.75 \sigma_{0 y}}{f_{R d, y}}\right)^{2}- \\
& -\frac{0.75 \sigma_{0 y}\left(0.75 \sigma_{0 x}+\sigma_{m b}\right)}{f_{R d, x} f_{R d, y}}+\left(\frac{\tau_{S d}}{f_{R d}}\right)^{2} \leq 1.0 ;
\end{aligned}
$$

- for point 1 according to Fig. 3, b:

$$
\begin{aligned}
& \left(\frac{\sigma_{m b}+0.75 \sigma_{1 x}}{f_{R d, x}}\right)^{2}+\left(\frac{0.75 \sigma_{1 y}}{f_{R d, y}}\right)^{2}- \\
& -\frac{0.75 \sigma_{1 y}\left(0.75 \sigma_{1 x}+\sigma_{m b}\right)}{f_{R d, x} f_{R d, y}}+\left(\frac{\tau_{S d}}{f_{R d}}\right)^{2} \leq 1.0 ;
\end{aligned}
$$

- for point 2 according to Fig. 2, b:

$$
\left(\frac{\sigma_{m b}+0.75 \sigma_{2 x}}{f_{R d, x}}\right)^{2}+\left(\frac{\tau_{S d}}{f_{R d}}\right)^{2} \leq 1.0 .
$$

\section{Numerical model of I-beam girder}

There has been prepared a comparison of the results obtained by using FEM and analytical method. It has several goals. Firstly, in terms of verifying the correctness of the proposed method of modeling the girder. Second, analysis of the parameter $n$ impact on the results obtained and their accuracy.

In the numerical simulation, an HEB 300 I-beam crane girder with a span of $10 \mathrm{~m}$ and capacity of $10 \mathrm{t}$ was used. The span of the hoisting winch wheels was $0.795 \mathrm{~m}$. In the presented model, the construction of headstocks and other unnecessary elements of the crane were omitted. The model was loaded at the middle of its span. Geometrical dependencies are shown in Fig. 3.

The N, mm, MPa system of units was applied, so the results of the stresses are in MPa and displacements are shown in $\mathrm{mm}$. The load-carrying structure was made from S355, where the limit design stress for sheets with thickness $<63 \mathrm{~mm}$ is $305 \mathrm{MPa}$ [21]. Standardized general purpose quadratic shell elements S8R and general purpose quadratic brick elements with reduced integration points C3D20R from Abaqus 6.13 Software Documentation were used [23]. The model presented in Fig. 4 consists of 1413688 elements and 1641297 nodes.

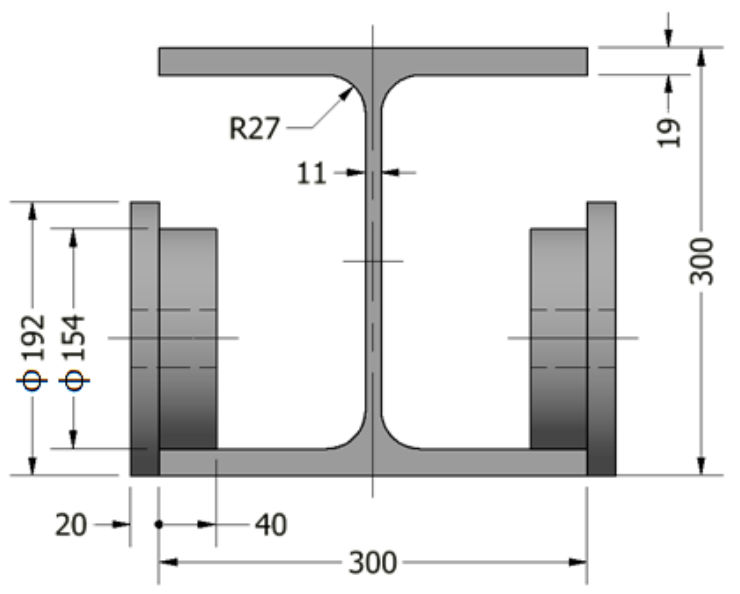

a

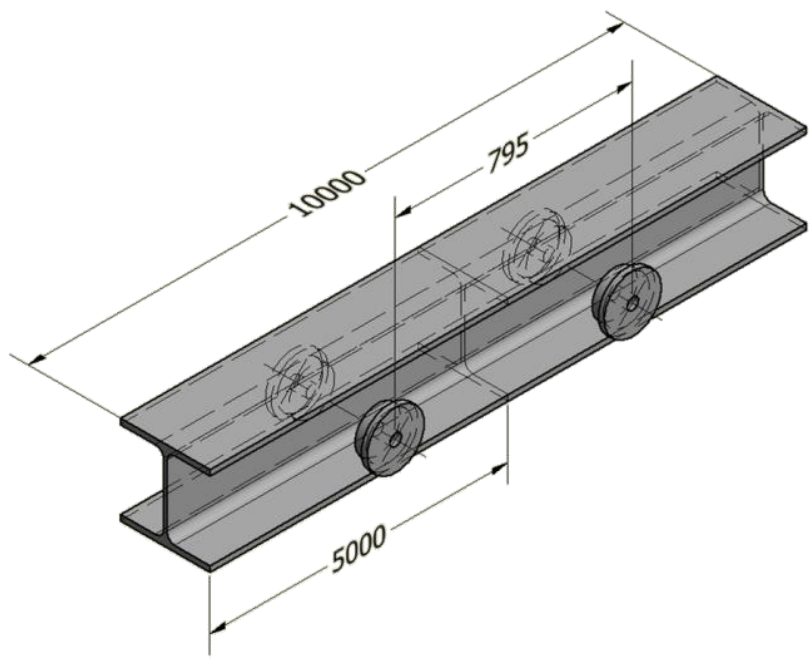

b

Fig. 3 Model dimensions: a - general geometric data of I-beam girder; b-general geometric data of traversing hoist

The boundary conditions were applied by the reference points, which are combined with the construction by using an MPC beam type connector. Construction of the girder was divided into three parts - two surface types and one as a solid type (in order to shorten the calculation time). These parts are combined with each other by using a shellto-solid coupling, which connects the side surface of the solid model with the edge of the shell. Load was applied by adding forces to the wheel axles of the hoist by using kinematic coupling constraints. Load at the bottom flange of the girder was applied by using node-to-surface type contact elements. Between the contact of the wheel and the surface of the lower flange of the girder a friction coefficient with a value of 0.15 is used, which is true for connection between steel and steel. In the simulation gravity as an acceleration value of $9.81 \mathrm{~m} / \mathrm{s}^{2}$ was also applied, which gives the opportunity to take into account the mass of the elements of the construction used. 


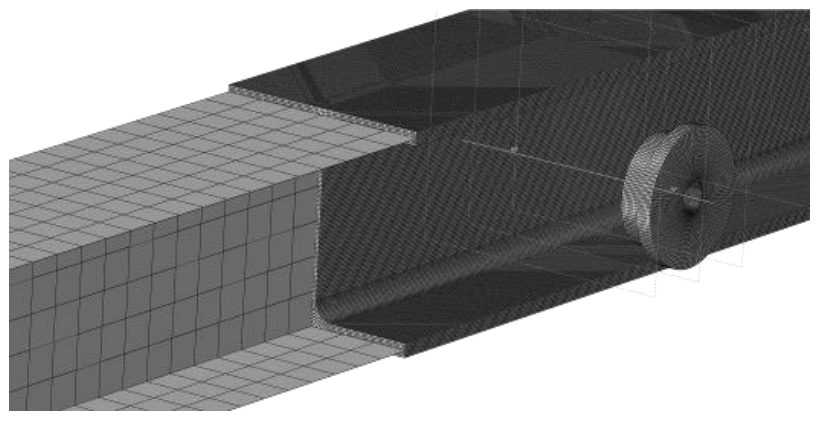

$\mathrm{a}$

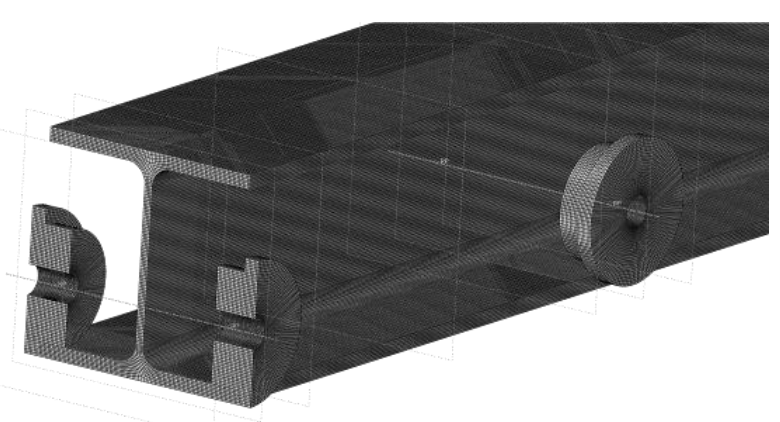

$\mathrm{b}$

Fig. 4 FEM model: a - connection between solid and shell partsl; b - solid model with wheel cross-section

\section{Simulation results}

The simulation results are presented as stress maps using Huber-Mises-Hencky theory and are shown in Figs. 5 and 6 . These figures show maps of the stresses in the middle (modelled as a solid) part of the girder.
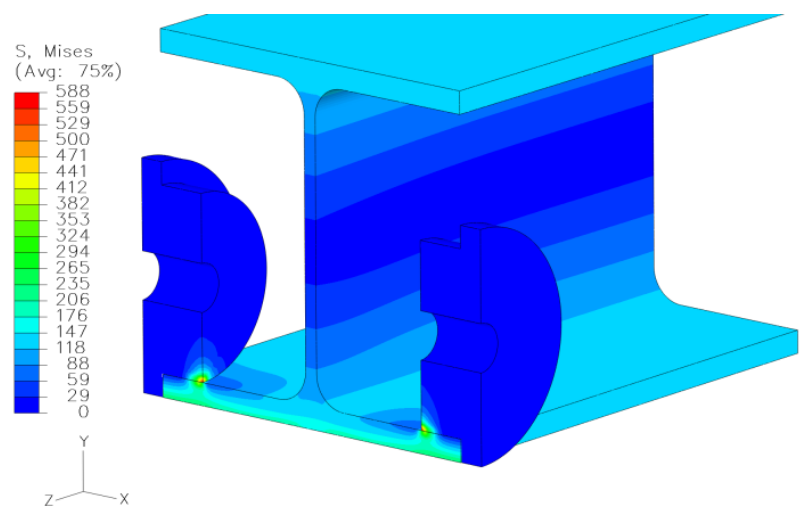

a

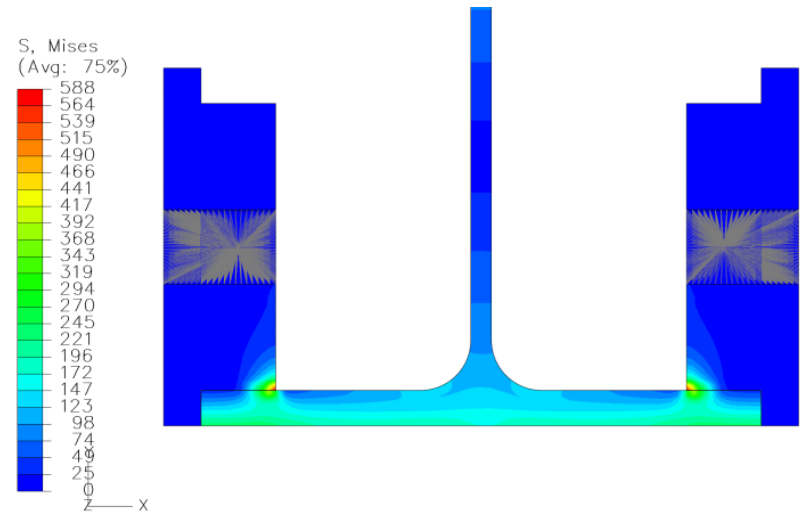

Fig. 5 Stress in I-beam according to Huber-Mises-Hencky theory (with wheels and mesh): a - isometric view; b - wheel cross-section view
These make it possible to obtain the values of the stress at any point of the cross-section of the I-beam, especially on fillets or places where the bottom flange goes inside to the middle part of the I-beam.

Fig. 6 shows maps of the stresses at the top and the bottom of the girder, where the influence of the local and main bending of the bottom flange, which is connected with loading of the construction by wheels, can be seen. The maximum values of the stress are presented on the bottom flange of the girder, mainly on the connection between the wheels and the top surface of the bottom flange of the girder. The maps of stresses presented in Fig. 2 at the cross-section of the bottom flange of the girder are the basis for determining the stress values at the so-called characteristic points presented in Figs. 2 and 7.
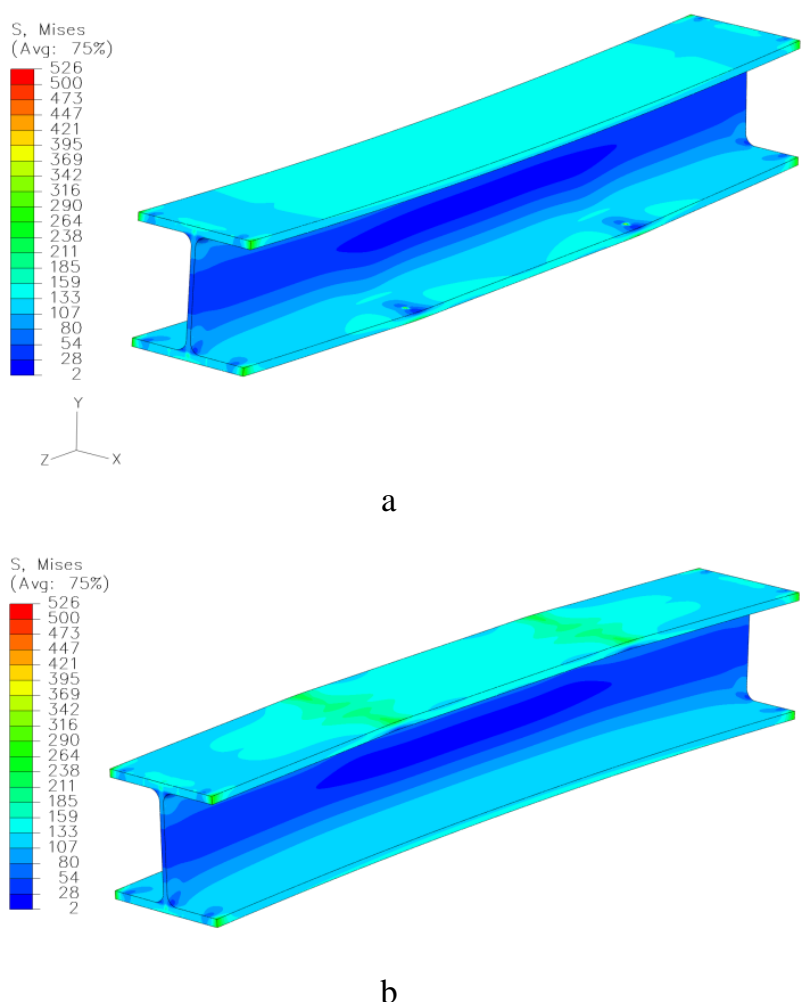

Fig. 6 Stress in I-beam according to Huber-Mises-Hencky theory (without wheels): $\mathrm{a}-$ top; $\mathrm{b}$ - bottom

\section{Comparison of calculations obtained by the FEM and analytical methods}

Fig. 7 shows the stress measurement points and comparison of values obtained analytically, as well as the values obtained through numerical calculations.

The values of stresses at characteristic points 0 , 1,2 presented in normative documents are connected with the value of coefficient $\mathrm{n}$ (which is the dimension between the side of the bottom surface of the flange and the place where the force is applied). Determination of the $n$ coefficient value is hard when using loading of the construction as a non-concentrated force. That is the main reason why the values of stress obtained are a little different from those given by the normative documents.

As can be seen in Table 2, the differences are $3.5 \div 15 \%$ for $n_{1}=20,2 \div 13 \%$ for $n_{2}=30,6 \div 14 \%$ for $n_{3}=40$. The most discussable point is point 0 , where the bottom flange of the girder goes into the middle part of the 
girder. There, a 10 to $15 \%$ difference occurs because the analytical values obtained by the normative documents do not include the fillets between the middle part of the girder at the lower and upper flanges. This has the major effect of lowering the values of stress at the concentration point.

Comparison of the analytical and FEM methods shows similar results at major stress points. Both the analytical method according to [20] and the numerical modelling may be used in the design of the main girders of overhead cranes. The differences are mainly due to modelling the load in a different way - in the analytical method force is added as concentrated force (at only one point), in FEM it is linear. The FEM method seems to be more accurate and gives a wider range of results, moreover allowing checking of the reinforced structures (weld-overlay).

Table 2

Comparison of stress values

\begin{tabular}{|c|c|c|c|c|}
\hline Type of calcu- & \multirow{2}{*}{$\begin{array}{c}\text { Results } \\
\text { lation }\end{array}$} & & \multicolumn{3}{|c|}{ Point No } \\
\cline { 2 - 5 } FEM for & Stress [MPa] & 226.6 & 235.4 & 193.4 \\
\cline { 2 - 5 }$n_{1}=20 \mathrm{~mm}$ & Difference [\%] & 0 & 0 & 0 \\
\hline Analytical for & Stress [MPa] & 241.9 & 243.7 & 222.2 \\
\cline { 2 - 5 }$n_{1}=20 \mathrm{~mm}$ & Difference [\%] & 6.72 & 3.51 & 14.94 \\
\hline Analytical for & Stress [MPa] & 214.7 & 230.3 & 217.1 \\
\cline { 2 - 5 }$n_{2}=30 \mathrm{~mm}$ & Difference [\%] & -5.25 & -2.19 & 12.28 \\
\hline Analytical for & Stress [MPa] & 194.9 & 221.4 & 212.4 \\
\cline { 2 - 5 }$n_{3}=40 \mathrm{~mm}$ & Difference [\%] & -13.98 & -5.98 & -9.87 \\
\hline
\end{tabular}

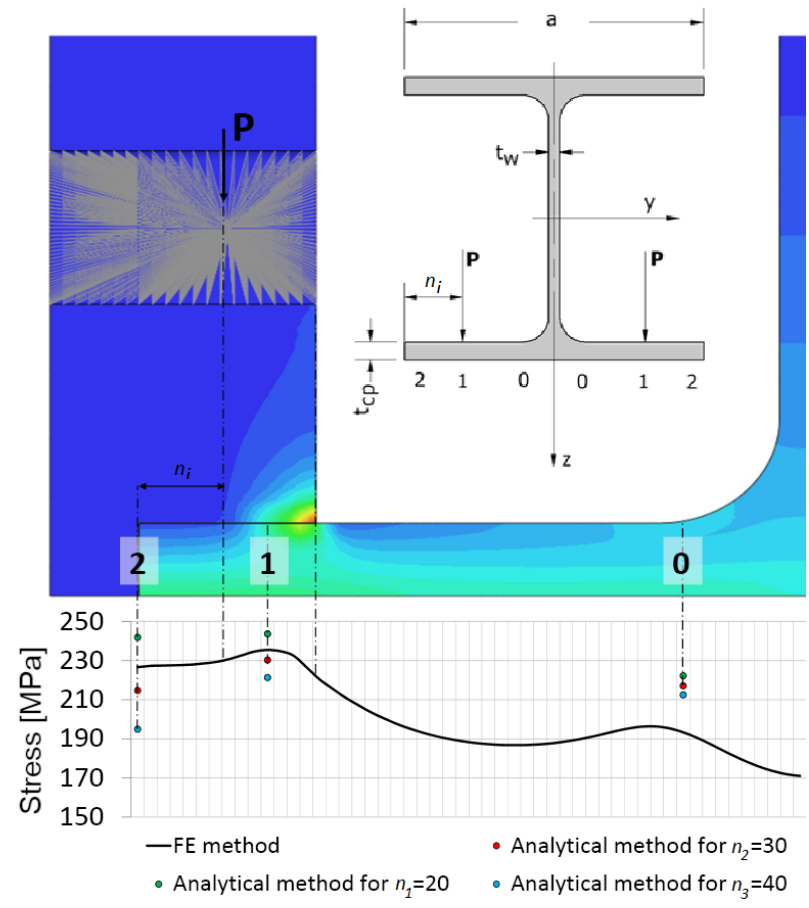

Fig. 7 Stress in I-beam (half of the cross-section) according to Huber-Mises-Hencky theory (with wheel), where: $P$ - local bending force; $t_{w}$ - thickness of the web; $n$-distance from the girder edge to the point of load application; $t_{c p}$ - theoretical thickness of the flange; $a$ - width of the flange

\section{Conclusions}

In the case of the crane, the dimensioning of the main girder for an overhead hoist or winch is to be carried out on the basis of the standard design of cranes using formulas (7-9). It is also necessary in this regard to take into account, beyond the general bending, additional components of the stress associated with local bending of the flanges by the crane or winch wheelsets. However, for strengthening of the lower flange the provisions of Eurocode 3 and the Finite Element Method should be applied. For dimensioning of the fixed roadway for suspended hoists or trolleys, the proper normative act is Eurocode 3, the standard for the static calculation and design of steel structures.

It seems to be necessary to develop analytical methods taking into account both the real way of modelling the load acting on the flanges of the I-beam (linear load) and the rounding and notches at the side of the penetration of the bottom flanges into the web. The aim of the analytical method is to adopt in the calculations infinitely long panels with the specified width, such that the connection is strengthened, i.e., to get rid of the notch stress by rounding, thereby giving lower stress values in comparison to the values obtained by analytical calculations. Modelling of loads causing local deformation of the lower flanges poses several problems, mainly due to the number of elements and the long calculation time. Note, however, that the analytical method contains many simplifications due to which the results obtained by this method may be inaccurate. The value and suitability of the proposed method, in terms of the values obtained for strengthening the lower flange, the ribbing effect, fatigue tests, and reinforcing ribs, should be verified.

\section{References}

1. Pypno, C. 2011. Means of Transport, Katowice: Silesian University of Technology, 232 p. (in Polish).

2. Verschoof, J. 2002. Cranes - Design, Practice, and Maintenance, Professional Engineering Publishing Ltd., London and Bury St Edmunds, UK. 329 p.

3. Pavlović, G.; Stepanovic, A.; Vidaković, J.; Savković, M.; Zdravković, N. 2015. Design optimization of the box section of the single-girder bridge crane by generalized reduced gradient algorithm, IMK-14 - Istraživanje i Razvoj u Teškoj Mašinogradnji 21(2015) (in Serbian).

4. Zrnić, N.; Bošnjak, S.; Gašić, V. 2008. Loading capacities curves for I-section runway beams according to bottom flange bending and lateral buckling, Machine Design, 181-186 p.

5. Kohut, P.; Gąska, A.; Holak, A.; Ostrowska, K.; Sladek, J.; Uhl, T.; Dworakowski, Z. 2014. A structure's deflection measurement and monitoring system supported by a vision system, Technisches Messen 81(12): 635-643.

http://dx.doi.org/10.1515/teme-2014-1057.

6. Matyja, T. 2010. Remarks on methods of calculating the crane load caused by running onto the track roughness, Transport Problems 5(1): 71-82.

7. Gąska, D.; Haniszewski, T. 2016. Modelling studies on the use of aluminium alloys in lightweight load-carrying crane structures, Transport Problems 11(3): 13-20. http://dx.doi.org/10.20858/tp.2016.11.3.2.

8. Davidson, J.; Yoo, C. 2003. Effects of distortion on the strength of curved I-shaped bridge girders, Transportation Research Board 2003 Annual Meeting. http://dx.doi.org/10.3141/1845-06.

9. Gąska, D.; Margielewicz, J.; Haniszewski, T.; 
Matyja, T.; Konieczny, Ł.; Chróst, P. 2015. Numerical identification of the overhead travelling crane's dynamic factor caused by lifting the load off the ground, Journal of Measurements in Engineering 3(1): 1-8.

10. Trahair, N.S. 2009. Lateral distortional buckling of monorails, Engineering Structures 31: 2873-2879. http://dx.doi.org/10.1016/j.engstruct.2009.07.013.

11. Hughes, A.; Iles, D.; Malik, A. 2011. Design of Steel Beams in Torsion, SCI, 133p.

12. Smoczek, J.; Szpytko, J. 2014. Evolutionary algorithmbased design of a fuzzy TBF predictive model and TSK fuzzy anti-sway crane control system, Engineering Applications of Artificial Intelligence 28: 190-200. http://dx.doi.org/10.1016/j.engappai.2013.07.013.

13. Madhavan, M.; Davidson, J.S. 2005. Buckling of centerline stiffened plates subjected to uniaxial eccentric compression, Thin-Walled Structures 43(8): 1264-1276. http://dx.doi.org/10.1016/j.tws.2005.03.013.

14. Ben, T.; Yen, B.; Kim, D.; Wilson, J. 2006. Evaluation of Displacements and Stresses in Horizontally Curved Beam, ATLSS Reports, Paper 74, 249 p.

15. White, D.; Zureick, A.; Phoawanich, N.; Se-Kwon, J. 2001. Development of Unified Equations for Design of Curved and Straight Steel Bridge and Girders, School of Civil and Environmental Engineering Georgia Institute of Technology, $551 \mathrm{p}$.

16. Mohebkhah, A. 2011. Lateral buckling resistance of inelastic I-beams under off-shear center loading, ThinWalled Structures 49: 431-436. http://dx.doi.org/10.1016/j.tws.2010.11.007.

17. ISO 16881-1:2005 Cranes - Design calculation for rail wheels and associated trolley track supporting structure.

18. FEM 9.341:1983-10. Series lifting equipment - Rules for the design of series lifting equipment, Local girder stresses.

19. EN 1993-6:2009. Eurocode 3: Design of steel structures. Part 6: Crane supporting structures.

20. EN 15011:2011+A1:2014. Cranes - Bridge and gantry cranes.

21. EN 13001-3.1:2011: Cranes - General Design - Part 3-1: Limit States and proof competence of steel structure.

22. EN 13001-2:2011: Crane safety - General design - Part 2: Load actions.

23. Abaqus 6.13 documentation. Dassault Systems 2014.

D. Gąska, T. Haniszewski, J. Margielewicz

\section{I-BEAM GIRDERS DIMENSIONING WITH \\ NUMERICAL MODELLING OF LOCAL STRESSES IN WHEEL-SUPPORTING FLANGES}

S u m m a r y

The article presents one-girder roadway structures for suspended cranes, conveyors and other machinery, as well as different ways of dimensioning them, taking into account the specifics of the state of the load acting on the lower flange of the roadway in accordance with the new standard EN15011:2011+A1:2014. In addition, an example of numerical modelling, using the finite element method, of an overhead travelling crane I-beam girder, being the roadway of a travelling hoist, is presented. The focus is primarily on local stresses occurring in the lower flange, which arise as a result of the occurrence of pressure from the wheels. In addition to the dominant stresses from general bending, the phenomenon of lower flange deflection is of great importance in terms of the final dimensions of the girder. The simulation results were compared with the results of analytical calculations.

Keywords: I-beam, dimensioning, local stress, numerical modelling.

Received March 01, 2016

Accepted June 08, 2017 